\title{
A Sensitive A $\beta$ Oligomerization Assay for Identification of Small Molecule Inhibitors
}

\author{
Amanda M. Gonzales and Robert A. Orlando*
}

Department of Biochemistry and Molecular Biology, University of New Mexico, School of Medicine, MSC08 4670, 1 University of New Mexico, Albuquerque, New Mexico 87131, USA

\begin{abstract}
Amyloid deposits found in Alzheimer's disease result from aggregation of A $\beta$ peptide which leads to loss of synaptic function, chronic microglial activation and cognitive impairment. Because of this, identification of small molecule inhibitors of $A \beta$ aggregation as potential therapeutics is a topic of current interest. The majority of inhibitor screening approaches rely on in vitro assays that lack the necessary sensitivity to distinguish low-molecular weight $A \beta$ oligomers from larger, more advanced-stage fibrillar structures. Differentiating between these two structures is of vital concern since recent studies indicate that small, early-stage $A \beta$ oligomers are the most neurotoxic form of peptide aggregate. To address this limitation, we have explored the adaptability of a recently described ELISA-based assay for discovery of small molecule inhibitors of $A \beta$ oligomerization. Results show that this assay is highly sensitive as it is able to quantify $A \beta$ oligomers with as little as $80 \mathrm{nM}$ input peptide. In addition, data were obtained re-confirming the function of curcumin as a potent inhibitor of $\mathrm{A} \beta$ aggregation ( $\mathrm{IC}_{50}=2 \mu \mathrm{M}$ ) and defining its inhibitor:peptide functional stoichiometry. Further examination of other known anti-aggregation compounds showed that this assay is able to discriminate between inhibitors of early-stage, low-molecular weight oligomers and later-stage, high-molecular weight fibrillar structures. These findings indicate that this new ELISA-based assay is capable of identifying novel small molecule inhibitors that function during the initial stages of $A \beta$ peptide assembly.
\end{abstract}

Keywords: Alzheimer, amyloid, oligomer, inhibitor, curcumin, EGCG.

\section{INTRODUCTION}

Histological examination of hippocampal and neocortical tissues from individuals afflicted with Alzheimer's disease reveals a hallmark feature of this progressive disorder, $\beta$ amyloid plaques. It is now well established that $A \beta$ peptide is a major component of these focal deposits. The molecular events leading to amyloid deposition are still under intense investigation; however, evidence is accumulating that suggests plaque formation is a result of a perturbation in the normal equilibrium of $A \beta$ peptide formation and peptide clearance [1-3]. The $A \beta$ peptide originates from what is believed to be normal processing of the amyloid precursor protein (APP). APP, a transmembrane protein, is cleaved in two successive proteolytic reactions to release $A \beta$ peptide, which is either 40 or 42 amino acids in length depending on its intramembrane cleavage site. Once formed, it is thought that $A \beta$ is cleared through normal drainage function of the cerebral spinal fluid (CSF) [4-6]. A $\beta$-related pathologies develop when free peptide, once reaching a critical concentration, forms insoluble oligomers which seed further aggregation eventually leading to the formation of characteristic amyloid lesions. Although amyloid plaques certainly contribute to neuronal damage in $\mathrm{AD}$ patients, recent evidence has suggested that early stage, low molecular weight forms of $A \beta$ oligomers inhibit hippocampal long-term potentiation and

*Address correspondence to this author at the Department of Biochemistry and Molecular Biology, University of New Mexico, School of Medicine, MSC08 4670, 1 University of New Mexico, Albuquerque, New Mexico 87131, USA; Tel: 505-272-5593; Fax: 505-272-3518;

E-mail: rorlando@salud.unm.edu may in fact be the most neurotoxic form of $A \beta$ aggregates [7-10]. Because of this, reducing $A \beta$ oligomer load to maintain or restore cognition has become a clinically important objective.

Reducing or preventing deposition of $A \beta$ oligomers can be approached from several directions: by reducing the processing of APP to slow the generation of $A \beta$ peptide, by increasing $A \beta$ peptide clearance, or by inhibiting, or slowing, the rate of peptide aggregation. The final proteolytic step to generate $A \beta$ peptide involves the cleavage of APP by gamma-secretase. A number of secretase inhibitors have been identified through extensive drug screening and are now being examined for efficacy in late-Phase clinical trials [11]. Increasing the rate of $A \beta$ peptide clearance has been explored through the use of low-flow, ventriculoperitoneal shunts [12], originally designed to increase drainage of CSF for individuals with hydrocephalus [13]. Although a practical approach in theory, recent evidence has cast doubts if any benefits can be obtained for Alzheimer patients with this therapy [14]. Alternatively, prevention of $A \beta$ aggregation has been explored through the identification of small molecule inhibitors [15]. From these efforts, a number of useful lead compounds have been identified such as sulfonated anions, benzofuran derivatives, as well as other polyphenolbased compounds [16-20]. Evaluations of these lead compounds have utilized various methodologies including differential centrifugation, light scattering, fluorescent spectral shifts and SDS-PAGE mobility shifts [21], all of which measure large molecular aggregates of $\mathrm{A} \beta$ peptide. Although these assays have provided useful data for novel lead compound identification, they also harbor a number of critical 
constraints that limit their application in large-scale, semi- or high-throughput screening of small molecule chemical libraries. Also, because measurements are restricted to large molecular aggregates, these methods are less apt to identify inhibitors of early stage, low-molecular weight A $\beta$ peptide oligomers. The most notable drawback of these assays is their limited sensitivities. A $\beta$ oligomerization is a concentration dependent reaction, and for these assays to provide reproducible detection of this reaction, starting A $\beta$ peptide concentrations of $1-100 \mu \mathrm{M}$ are very often needed to drive the oligomerization process. Questions have arisen asking if these in vitro reactions are truly reflective of $\mathrm{A} \beta$ oligomerization in vivo since it is unlikely that localized brain levels of A $\beta$ peptide would ever reach these concentrations [22-25].

Another important consideration for inhibitor identification studies is mechanism of action. While the identity of a number of $A \beta$ oligomerization inhibitors have been reported, few address the stoichiometric relationship between inhibitor and peptide, and when calculated, suggest inhibitor to peptide ratios of no greater than one, or in some cases less than one [26-32]. Presuming that inhibitors must physically bind to peptide to prevent oligomerization [33, 34], it is difficult to imagine a mechanism of action where inhibitor to peptide ratios are less than 1 . Such questionable stoichiometric ratios could be due to the high concentrations of $A \beta$ peptide needed in these assays to initiate detectable oligomerization. These problems could be solved with an assay that requires a lower starting concentration of peptide and bears greater sensitivity of detection.

To address these challenges, we have explored the use of a highly sensitive ELISA-based method for detecting $A \beta$ oligomers for the purpose of identifying novel small molecule inhibitors of $A \beta$ aggregation. Based upon previous methods developed by LeVine [35] and El-Agnaf [36], the sensitivity of this approach permits the use of sub- $\mu \mathrm{M}$ concentrations of $A \beta$ peptide for initiation of the oligomerization reaction and more closely reflects amounts that can be expected in vivo. Most importantly, using lower peptide concentrations will focus inhibitor identification assays on the early stages of oligomer formation to more precisely target the most neurotoxic form of $A \beta$ aggregates [36]. And finally, an ELISA-based approach should not only allow for more cost effective screening of large chemical libraries, but should also permit a more accurate assessment of peptide:inhibitor stoichiometry for future studies aimed at identifying mechanism of action.

\section{MATERIALS AND METHODOLOGY}

\section{Reagents and Materials}

1,1,1,3,3,3-Hexafluoro-2-propanol (HFIP), dimethylsulfoxide (DMSO), fraction $\mathrm{V}$ bovine serum albumin and all buffer reagents were obtained from Sigma-Aldrich (St. Louis, MO). Tetramethylbenzidine (TMB) was purchased from Roche (Indianapolis, IN). Human A $\beta(1-42)$ was purchased from AnaSpec (San Jose, CA). NUNC MaxiSorp ELISA plates were obtained from eBioscience (San Diego, CA). Monoclonal antibody 4G8 specific for human A $\beta$ amino acids 17-24 (Fig. 1A) and horseradish peroxidase (HRP)-conjugated 4G8 were purchased from Signet Labs (Dedham, MA). Curcumin, ferulic acid, vanillin, rosmarinic acid, catechin, epigallocatechin gallate (EGCG) and resvera- trol were purchased from Cayman Chemicals (Ann Arbor, MI).

\section{Preparation of Monomeric A $\beta(1-42)$ Peptide}

$A \beta(1-42)$ peptide was dissolved in HFIP [35, 37] to a final concentration of $4 \mathrm{mg} / \mathrm{ml}$ and divided into $500 \mu \mathrm{g}$ aliquots. Aliquots were dried under a stream of sterile $\mathrm{N}_{2}$ and stored at $-20^{\circ} \mathrm{C}$ until use. Immediately preceding each experiment, aliquots were dissolved in DMSO to a final concentration of $1 \mathrm{mM}$. To ensure peptide was fully dissolved, solutions were sonicated for $15 \mathrm{~min}$ followed by heating at $60^{\circ} \mathrm{C}$ for an additional $15 \mathrm{~min}$. Any unused peptide was discarded.

\section{A $\beta$ Peptide Oligomerization Reactions}

A $\beta$ peptide from DMSO stock was diluted to the indicated concentrations either into phosphate buffered saline, pH 7.2 (PBS) alone or into test compound, pre-diluted into PBS. Stock solutions of all test compounds were made with DMSO for solvent compatibility. Dilutions were large enough to ensure that final DMSO concentrations were consistently $<1 \%$ in the reaction mix. Reactions were incubated at $37^{\circ} \mathrm{C}$ for $24 \mathrm{~h}$ and then processed for capture ELISA.

$\mathrm{A} \beta$ oligomer reactions were fractionated by $12 \%$ polyacrylamide gel electrophoresis (PAGE) by mixing reactions with an equal volume of $2 \mathrm{X}$ native sample buffer $(125 \mathrm{mM}$ Tris, $\mathrm{pH}$ 6.8, 20\% glycerol, $0.02 \%$ bromophenol blue) and employing a standard Tris-Glycine buffer system without sodium dodecyl sulfate. After separation, gels were silver stained using the Morrissey method [38] and photographed with a Nikon D90 SLR digital camera.

\section{Capture ELISA for A $\beta$ Oligomer Detection}

NUNC Maxisorp high-binding ELISA plates were coated with $\mathrm{mAb} 4 \mathrm{G} 8$ diluted to $2 \mu \mathrm{g} / \mathrm{ml}$ in PBS for a minimum of $16 \mathrm{~h}$ at $4{ }^{\circ} \mathrm{C}$. After rinsing plates with PBS and blocking nonspecific sites with PBS-T/B (PBS containing $0.1 \%$ Tween$20,1 \%$ bovine serum albumin) for $1.5 \mathrm{~h}, \mathrm{~A} \beta$ peptide oligomerization reactions were added to wells and incubated with immobilized capture $\mathrm{mAb}$ for $2 \mathrm{~h}$. Wells were rinsed three times with TBS-T $(20 \mathrm{mM}$ Tris- $\mathrm{HCl}, 150 \mathrm{mM} \mathrm{NaCl}$, $\mathrm{pH} 7.4,0.05 \%$ Tween-20) using a Biotek ELx50 automated plate washer. HRP-conjugated mAb 4G8 was added to wells at $1 \mu \mathrm{g} / \mathrm{ml}$ diluted into PBS-T/B and incubated at $23^{\circ} \mathrm{C}$ for 1 h. Unbound secondary antibody was removed by rinsing three times with TBS-T and bound antibody was measured following addition of TMB reagent. TMB reaction was terminated after $\sim 10 \mathrm{~min}$ with the addition of an equal volume of $1 \mathrm{M} \mathrm{H}_{2} \mathrm{SO}_{4}$. Absorbance was recorded at $450 \mathrm{~nm}$ with a reference wavelength of $650 \mathrm{~nm}$ using a Molecular Devices SpectraMax 384 Plus plate reader.

\section{Statistical Analyses}

All experimental protocols were carried out in at least triplicate points to determine mean values. Error bars represent standard deviation from mean values.

\section{RESULTS}

The $A \beta$ oligomerization assay presented here is directly adapted from the method published by LeVine [35]. The principle of this assay employs the use of one anti-A $\beta$ monoclonal antibody as both capture- and detection-antibody for 
single epitope recognition (Fig. 1A). With this format, monomeric peptide will be captured by the immobilized $\mathrm{mAb}$, but not detected by the same mAb since the epitope is already occupied (Fig. 1B). By contrast, the detection $\mathrm{mAb}$ will identify multimeric peptide complexes due to the availability of unoccupied epitopes. Inhibitors of oligomerization are identified simply by a reduction or loss of detectionantibody binding.

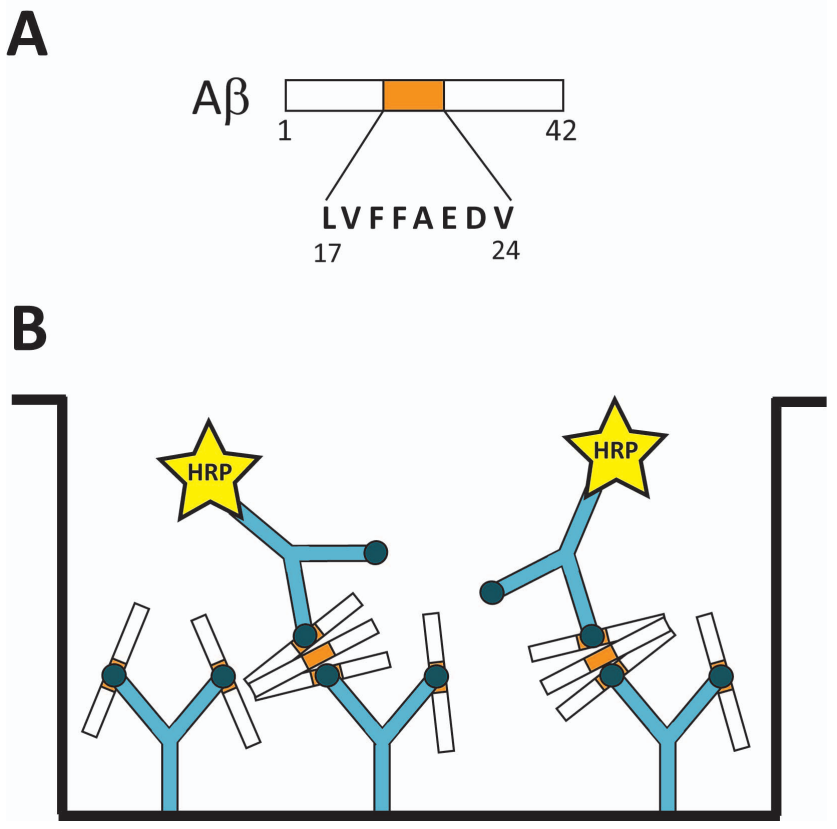

Fig. (1). Principle of the ELISA-based A $\beta$ oligomer detection assay. (A) Human $A \beta(1-42)$ and location of the mAb 4G8 epitope (amino acids 17-24). (B) Total A $\beta$ peptide mixture (monomers and oligomers) are incubated with immobilized capture mAb 4G8. Both monomers and oligomers are able to bind to immobilized $\mathrm{mAb}$ 4G8. Detection of bound peptide is made with horseradish peroxidase (HRP)-conjugated mAb 4G8 recognizing the same epitope as the capture antibody. With this configuration, the 4G8 epitope within the monomeric peptide will be occupied by the 4G8 capture antibody and only multimeric complexes with additional 4G8 epitopes that are not engaged by the capture antibody will be bound by the detection antibody and provide a signal.

The first objective was to test the sensitivity of this assay by determining the lowest input amount of $A \beta$ peptide necessary to form measurable levels of $A \beta$ oligomers. For this, $\mathrm{A} \beta$ peptide was diluted to concentrations across 3-log units (10 $\mathrm{nM}$ to $10 \mu \mathrm{M}$ ) to assess the dynamic range of the assay. Oligomers were identified with as little as $80 \mathrm{nM}$ input $\mathrm{A} \beta$ peptide (Fig. 2). Oligomer formation was clearly dependent upon peptide concentration and reached maximal levels over a single order of magnitude of input peptide indicating a rapid first-order reaction. Based on these data, $200 \mathrm{nM}$ input A $\beta$ peptide concentration was chosen for all subsequent assays. Formation of low molecular weight oligomers with this concentration was confirmed by polyacrylamide gel electrophoresis followed by silver staining (Fig. 2, inset).

The capacity of this ELISA-based assay to identify small molecule inhibitors of $A \beta$ oligomerization was next tested using the polyphenolic natural product, curcumin. Curcumin

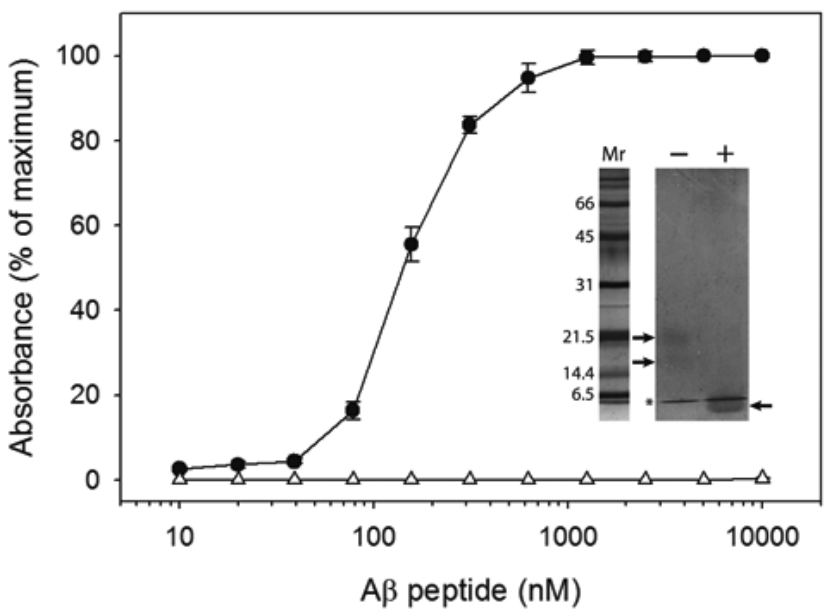

Fig. (2). A $\beta$ oligomerization quantified by capture ELISA. $\mathrm{A} \beta(1-42)$ peptide was diluted to the indicated concentrations in the absence $(\bullet)$ or presence $(\Delta)$ of $0.1 \%$ Tween-20 and incubated at $37^{\circ} \mathrm{C}$ for $24 \mathrm{~h}$. Tween- 20 has been shown to inhibit $\mathrm{A} \beta$ oligomerization and provide a negative control [35]. A $\beta$ oligomers were detected by capture ELISA; unconjugated mAb 4G8 was used as immobilized capture antibody, HRP-conjugated mAb 4G8 was used as detection antibody. Absorbance values shown (\% of maximum) were calculated as percent of absorbance measured with 10 $\mu \mathrm{M}$ input $\mathrm{A} \beta(1-42)$ peptide; this being the maximum absorbance recorded for this assay. Mean values were determined from six replicates. Error bars represent standard deviation from mean values. Inset, $200 \mathrm{nM} \mathrm{A} \beta$ peptide was incubated as above in the absence $(-)$ or presence $(+)$ of $0.1 \%$ Tween-20 and separated by PAGE followed by silver staining. Arrows indicate presence of low molecular weight oligomers (-) or monomeric peptide (+). Asterisk indicates the bromophenol dye front.

has recently been shown to be a potent inhibitor of $A \beta$ oligomerization both in vitro and in vivo [29]. A $\beta$ peptide was diluted directly into various concentrations of curcumin to a final concentration of $200 \mathrm{nM}$ and incubated at $37^{\circ} \mathrm{C}$ for 24 h. Oligomers were then quantified by capture ELISA. Curcumin was highly effective in inhibiting $A \beta$ oligomerization in a dose-dependent manner (Fig. 3). The $\mathrm{IC}_{50}$ value was calculated as $2 \mu \mathrm{M}$, which is in agreement with previously published values [29, 39].

The therapeutic benefits of curcumin as a dietary supplement are still debated largely because of its poor bioavailability $[40,41]$ and its propensity to be chemically unstable in an aqueous environment; degrading into ferulic acid and vanillin [42, 43]. Inquiries have been made into whether these products are able to mimic the anti-aggregation activity of curcumin. Byeon, et al. showed that ferulic acid can bind with reasonably high affinity to large $\beta$-amyloid fibrils [44]. Ferulic acid is also capable of destabilizing fibrillar structures, in addition to preventing fibril extension [45]. In contrast to results with ferulic acid, vanillin has been shown to inhibit formation of lower-molecular weight oligomers [46]; although concentrations of $\mathrm{A} \beta$ peptide $(45 \mu \mathrm{M})$ and vanillin $(300 \mu \mathrm{M})$ used in this study far exceeded what would be expected in vivo making a physiologic interpretation difficult. To re-examine the inhibitory capacity of ferulic acid and vanillin using an assay with greater sensitivity, $\mathrm{A} \beta$ oli- 


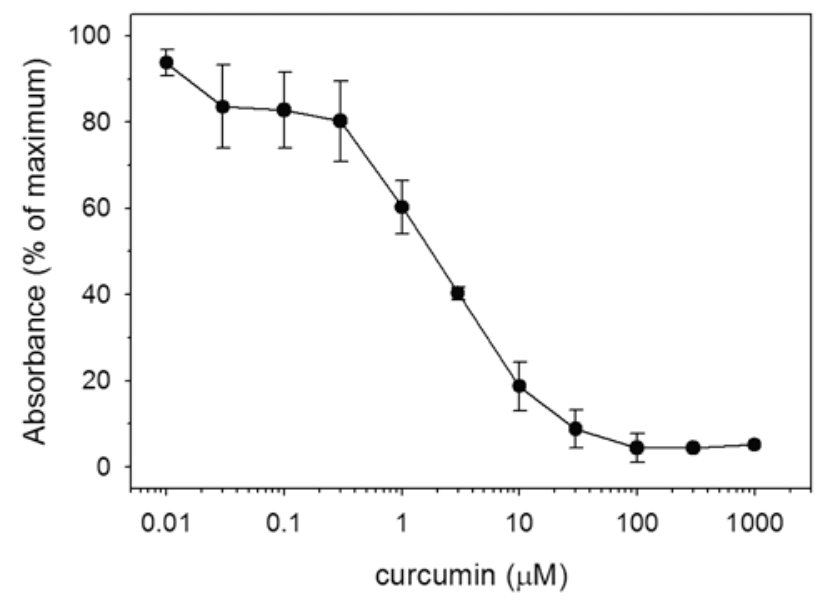

Fig. (3). Curcumin inhibits $A \beta$ oligomer formation in a dosedependent manner. $A \beta(1-42)$ peptide $(200 \mathrm{nM}$ final concentration) was mixed with the indicated concentrations of curcumin and incubated at $37^{\circ} \mathrm{C}$ for $24 \mathrm{~h}$. A $\beta$ oligomers were quantified as in Fig. (2).

gomerization was challenged with various concentrations of each compound, in parallel with curcumin, and measured by capture ELISA. Even with concentrations as high as $20 \mu \mathrm{M}$, no reduction in $A \beta$ oligomerization was measured by either compound (Fig. 4). These data indicate that the complete, diphenolic structure of curcumin is necessary to prevent earlystage oligomer formation.

As shown in Fig. (4) and by others [39, 47, 48], a structure-activity relationship exists between curcumin and $A \beta$ oligomerization with the polyphenolic platform being a necessary structural requirement. In this regard, other polyphenolic compounds have been tested and identified as inhibitors of $A \beta$ oligomerization $[49,50]$, but few of these have been examined in parallel with curcumin. Moreover, a range of $\mathrm{IC}_{50}$ values have been reported for each of these polyphe-

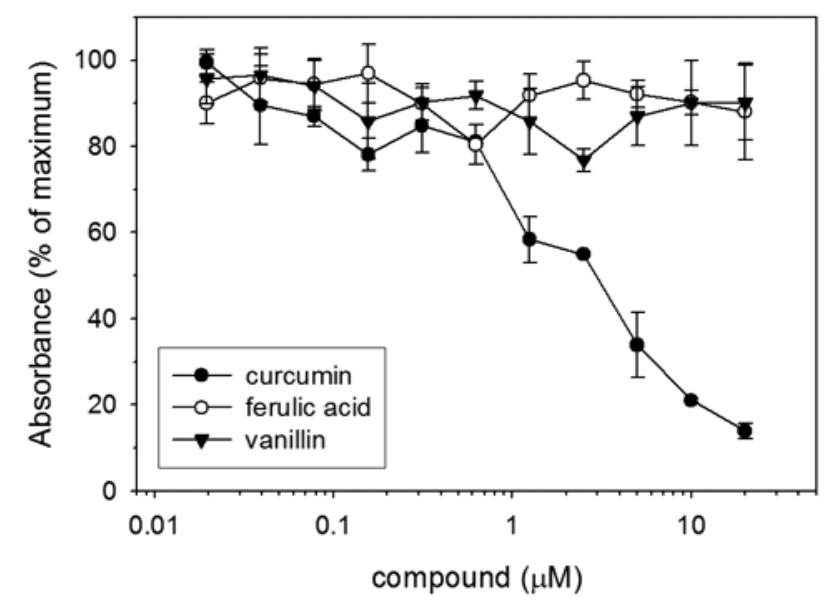

Fig. (4). Ferulic acid and vanillin have no effect on early-stage $A \beta$ oligomer formation. $A \beta(1-42)$ peptide (200 $\mathrm{nM}$ final concentration) was incubated with the indicated concentrations of curcu$\min (\bullet)$, ferulic acid (०) or vanillin $(\boldsymbol{\nabla})$ at $37^{\circ} \mathrm{C}$ for $24 \mathrm{~h}$. A $\beta$ oligomers were quantified as in Fig. (2). nols, but this may be due to the fact that these studies relied upon assays that require relatively high starting concentrations of $A \beta$ peptide because of their reduced sensitivities. To gain a better understanding of the potential of some of these compounds in relation to the activity of curcumin, the effects of rosmarinic acid, epigallocatechin gallate (EGCG), catechin and resveratrol (Table 1) on $A \beta$ oligomerization were tested in parallel with curcumin. Catechin and resveratrol demonstrated little anti-oligomerization activity, while rosmarinic acid inhibited $A \beta$ peptide aggregation only at the highest concentration tested, this being $20 \mu \mathrm{M}$ (Fig. 5). EGCG was capable of reducing peptide aggregation in a dose-dependent manner with an $\mathrm{IC}_{50}$ value of $\sim 8 \mu \mathrm{M}$. However, the anti-oligomerization activity of curcumin far surpassed that of any other test compound.

\section{DISCUSSION}

Aggregation of the $A \beta$ peptide is a hallmark event in the pathogenesis of AD. Formation of $A \beta$ oligomers leads to impairment of synaptic function [51], chronic microglial activation [52], and premature neuronal death. Because of this, there has been an extensive and widespread search for small molecule inhibitors to prevent formation of these toxic peptide aggregates. Previous assays designed to measure oligomerization, including spectroscopic and microscopic procedures, require large amounts of $\mathrm{A} \beta$ peptide to create sufficient quantities of aggregates to surpass the minimum threshold for detection. Such quantities far exceed what would be expected in $\mathrm{AD}$ diseased brains during initial nucleation of amyloid deposits raising questions if such reactions accurately represent the physiochemical parameters of oligomer formation in vivo. The majority of assays used for inhibitor identification apply dye-binding protocols that differentiate between free dye and dye bound to peptide aggregates by measuring spectral shifts. These dyes bind to peptide aggregates by non-specific, hydrophobic interactions and are unable to discern between low- versus highmolecular weight aggregates [53-58]. This has become of concern since recent studies suggest that the early stages of A $\beta$ peptide oligomerization forming low-molecular weight aggregates may represent the most toxic form in vivo [7, 9, $10,59]$. For these reasons, we sought to identify a more sensitive assay for molecular discovery screening regimens that is a better representation of the early stages of $A \beta$ oligomerization. The principle of the present study focuses on an ELISA-based capture assay for $A \beta$ oligomer detection [35, 36]. This ELISA format uses a single $A \beta$-specific $m A b$ for both antigen capture and detection and is capable of clearly distinguishing monomeric peptide from $A \beta$ oligomers. Importantly for our objectives, this assay also discerns earlystage, low-molecular weight soluble aggregates from laterstage, amyloid fibrils [36], and in this manner is better suited to identify inhibitors of the most critical stage of $A \beta$ peptide oligomerization.

We have explored the adaptability of this assay for discovery of small molecule inhibitors of the A $\beta$ peptide oligomerization process. Using $\mathrm{A} \beta \mathrm{mAb} 4 \mathrm{G} 8$ that is specific for residues 17-24, oligomer formation was easily measurable with as little as $80 \mathrm{nM}$ input peptide. This sensitivity is far greater than can be achieved by dye-binding or light scattering assays and comparable to the results reported by LeVine [35]. Several small molecule inhibitors of $A \beta$ 
Table 1. Chemical Structures of Compounds Tested in the ELISA-Based A $\beta$ Oligomerization Assay

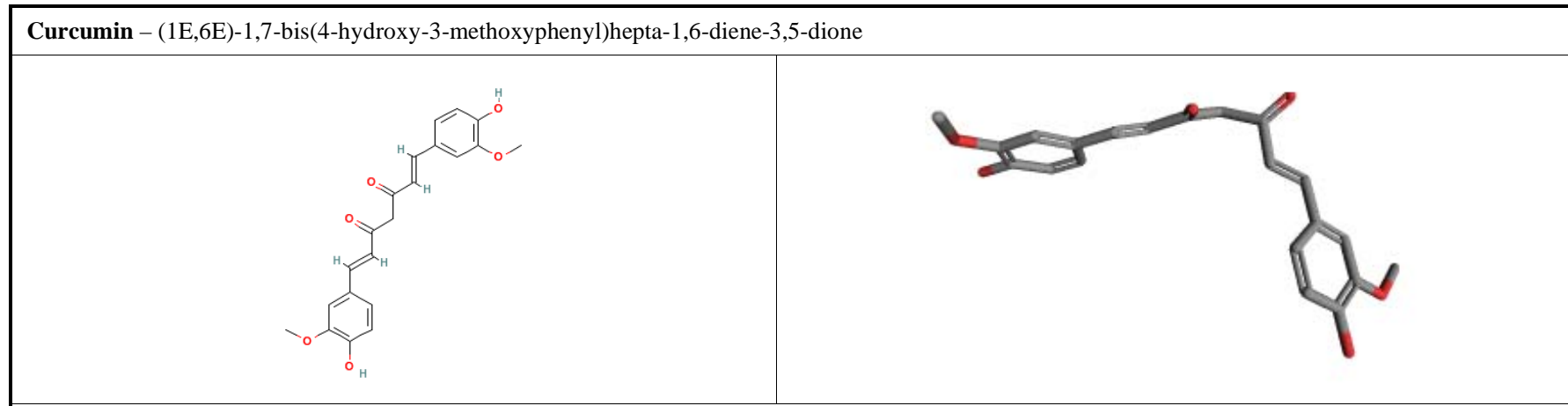

Ferulic acid - (E)-3-(4-hydroxy-3-methoxyphenyl)prop-2-enoic acid

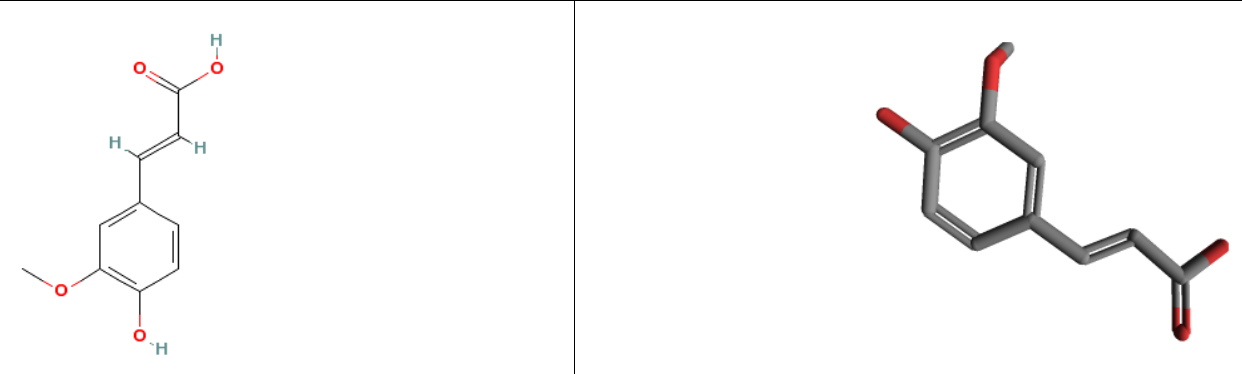

Vanillin - 4-hydroxy-3-methoxybenzaldehyde

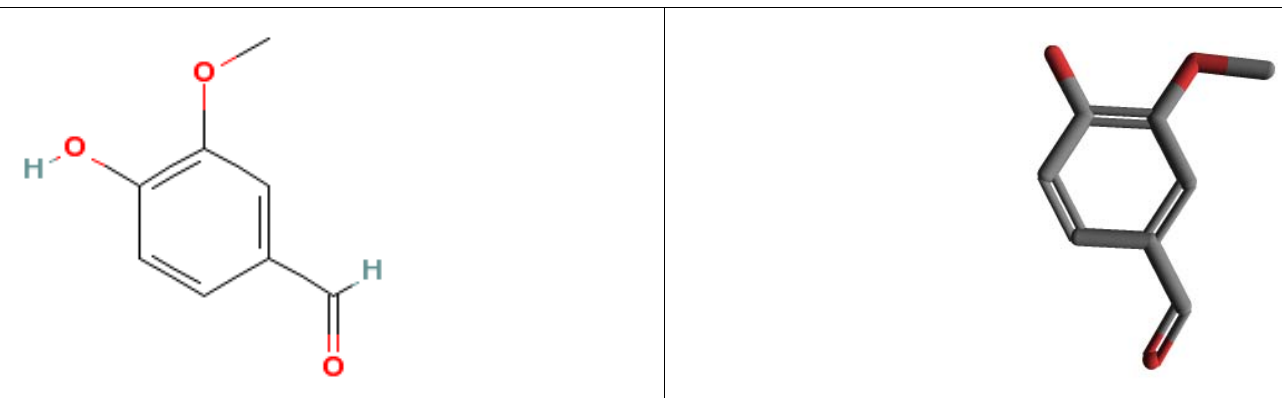

Rosmarinic acid - (2R)-3-(3,4-dihydroxyphenyl)-2-[(E)-3-(3,4-dihydroxyphenyl)prop-2-enoyl]oxypropanoic acid
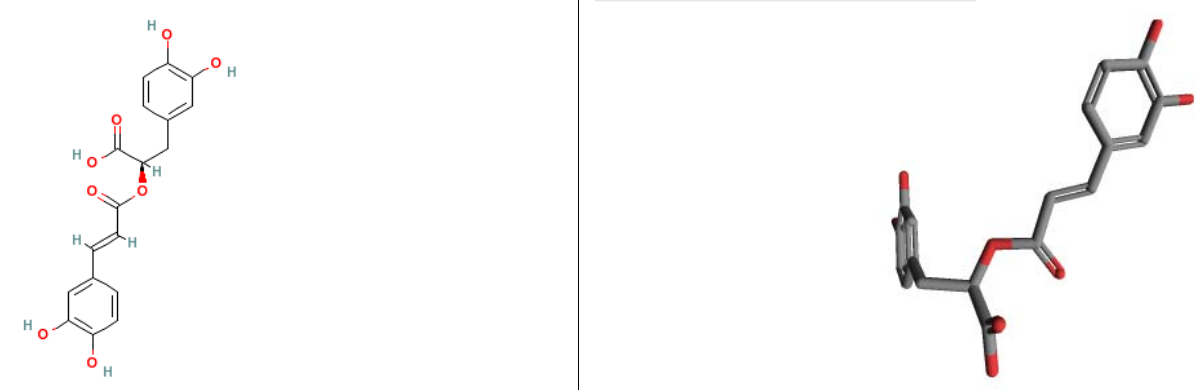

Epigallocatechin gallate - [(2R,3R)-5,7-dihydroxy-2-(3,4,5-trihydroxyphenyl)-3,4-dihydro-2H-chromen-3-yl] 3,4,5-trihydroxybenzoate
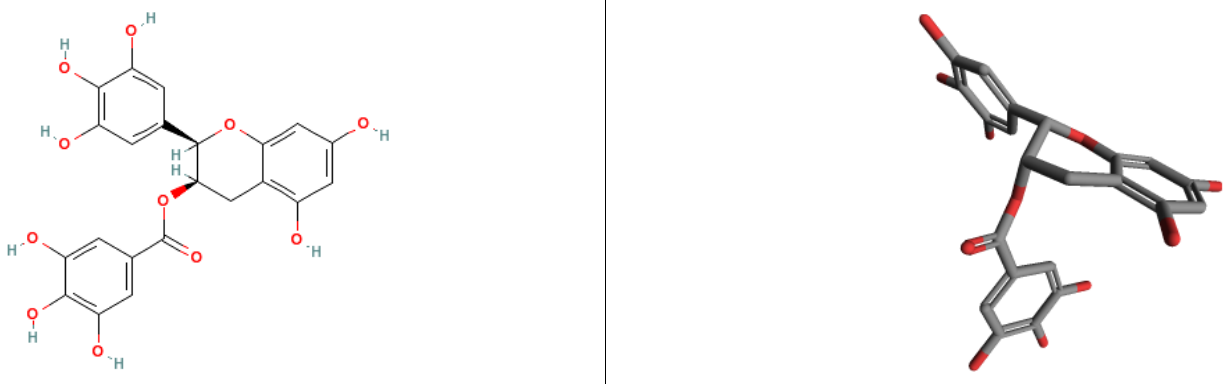
(Table 1). Contd.....

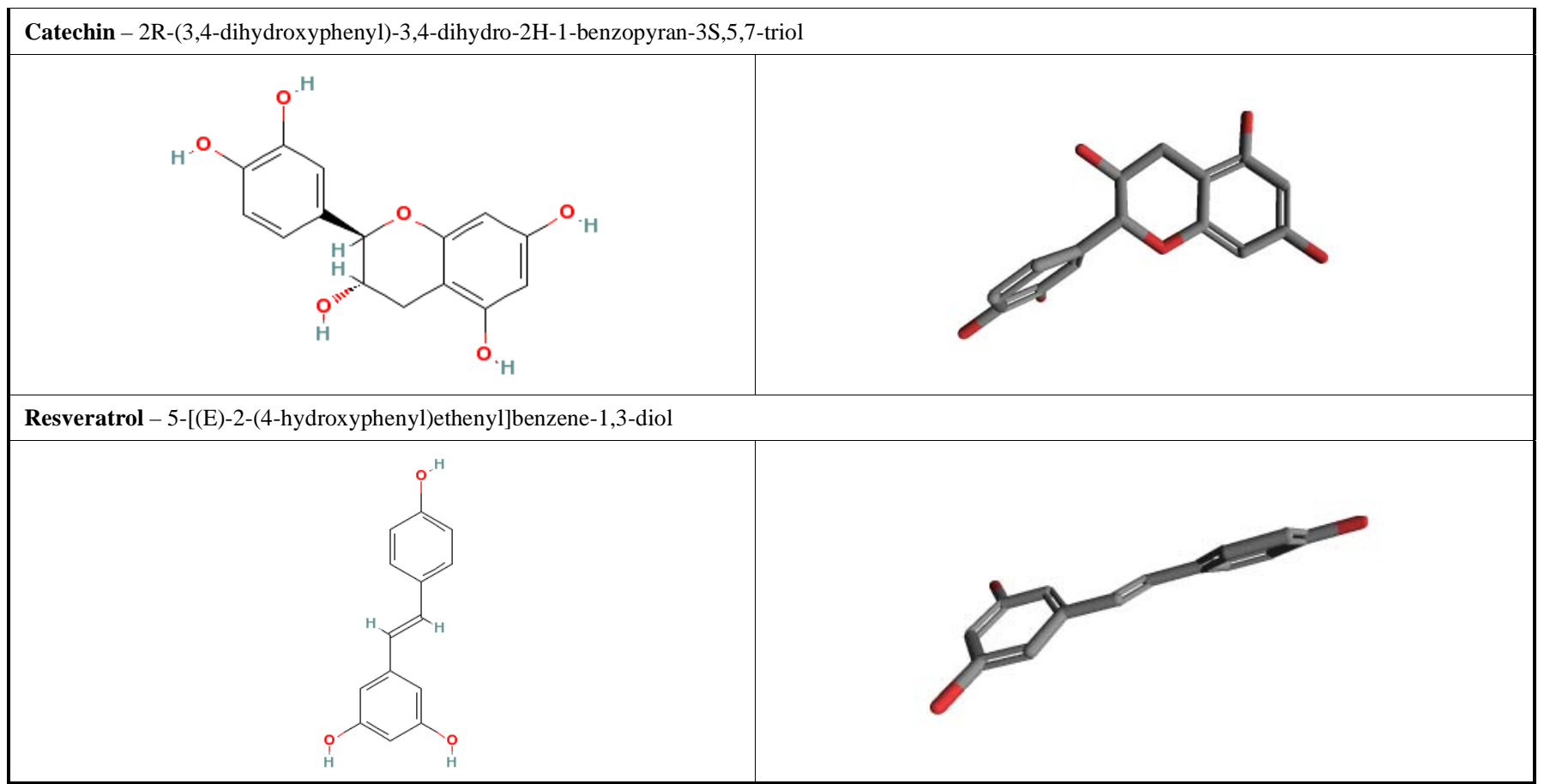

Common name followed by IUPAC name. Shown are 2-D and 3-D representations (PubChem Compound database, National Center for Biotechnology Information).

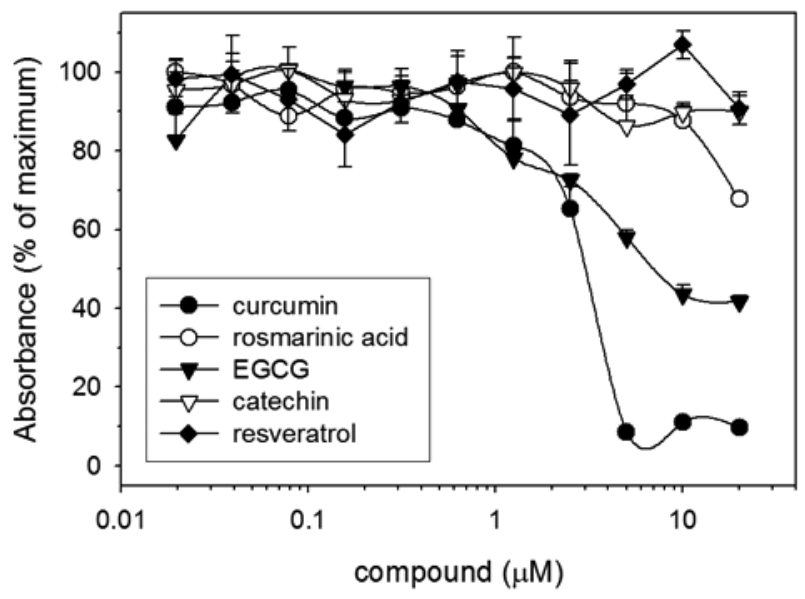

Fig. (5). Effects of rosmarinic acid, EGCG, catechin and resveratrol on early-stage $A \beta$ oligomer formation. $A \beta(1-42)$ peptide (200 $\mathrm{nM}$ final concentration) was incubated with the indicated concentrations of curcumin $(\bullet)$, rosmarinic acid (०), EGCG $(\boldsymbol{\nabla})$, catechin $(\nabla)$ or resveratrol $(\diamond)$ at $37^{\circ} \mathrm{C}$ for $24 \mathrm{~h}$. $\mathrm{A} \beta$ oligomers were quantified as in Fig. (2).

oligomerization, mostly polyphenolic compounds, have been identified using dye-binding or light scattering assays. Since these assays are unable to discriminate between low- and high-molecular weight oligomers, and thus early- versus late-stage $A \beta$ aggregation events, several of the most promising compounds (Table 1) were re-evaluated using the ELISA-based assay to assess their effectiveness as aggregation inhibitors during the early stages of peptide assembly. The first compound considered was curcumin. Curcumin is a natural product found in the rhizomes of the Curcuma longa family. It has a di-phenolic structure joined by $\alpha-\beta$ - unsaturated and $\beta$-diketone moieties. Curcumin has proven to be a potent inhibitor of $A \beta$ aggregation in vitro, capable of reducing amyloid deposition in vivo and improving cognitive function in an AD mouse model [29]. In spite of these positive results, serious challenges remain to transform curcumin into a viable therapeutic option due to its poor bioavailability [40, 41] and lability in an aqueous environment [42, 43]. Because of curcumin's polyunsaturated 7-carbon spacer arm and $\beta$-diketone moiety, it readily degrades into ferulic acid and vanillin [60]. Some reports have suggested that these products maintain activity as anti-aggregates even with the loss of their polyphenolic structure [44-46, 61]. This was challenged using the ELISA-based assay and their antiaggregation capacity was directly compared in parallel with curcumin. The results showed no measurable activity by ferulic acid or vanillin in preventing $A \beta$ peptide oligomerization. These findings reinforce the observation that a polyphenolic structure is a minimal requirement for an inhibitor of $A \beta$ aggregation.

Other small molecule inhibitors with polyphenolic structures have been identified that prevent $A \beta$ peptide aggregation [49, 50], but none of these have been quantitatively compared side-by-side with curcumin. Rosmarinic acid, EGCG, catechin and resveratrol are among the most potent found with $\mathrm{IC}_{50}$ values reported as $1.1,0.18,5.3$, and 5.6 $\mu \mathrm{M}$, respectively [49]. Rosmarinic acid is a natural polyphenol found in many culinary herbs such as lemon balm, rosemary, oregano, sage, thyme and peppermint. In addition to inhibiting $A \beta$ aggregation, a recent study has indicated that rosmarinic acid can directly bind $\beta$-amyloid fibrils and may serve as an in vivo imaging agent for non-invasive testing and tracking amyloid progression [62]. Catechin and its epimer, epicatechin, are the most common optical isomers found in nature. Catechins constitute about $25 \%$ of the dry weight of fresh tea leaves and are present in nearly all teas 
made from Camellia sinensis, including white tea, green tea, black tea and Oolong tea. Epigallocatechin contains an additional phenolic hydroxyl group as compared with catechin and its gallic acid ester, epigallocatechin gallate (EGCG), is the most abundant form of catechin found in tea. Tea catechins, especially their gallic acid esters, are known to inhibit fibrilization of $A \beta$ peptide and protect against $A \beta$ oligomer induced neurotoxicity [63, 64]. Resveratrol is a polyhydroxylated stilbene found in many foods, but is especially abundant in many varietals of red wine. By itself, resveratrol is a potent anti-oxidant which is thought to be responsible for the French Paradox [65]; relating to the low incidence of cardiovascular disease in a French population with high intake of saturated fats. In addition to its demonstrated capacity to inhibit $A \beta(25-35)$ fibril formation in vitro [16], resveratrol is also capable of promoting intracellular uptake and degradation of $A \beta$ through a proteosome-dependent mechanism [66] and protecting against $A \beta$-induced neurotoxicity $[67,68]$, possibly through activation of the NAD-dependent histone deacetylase, SIRT1 [69]. In the present study using the ELISA-based assay, catechin showed no inhibitory activity during the early stages of $A \beta$ oligomerization, whereas rosmarinic acid demonstrated some activity at the highest concentration tested. EGCG showed a clear dose-dependent inhibition of early stage oligomer formation; albeit with a 2 3 fold lower effectiveness than curcumin. These findings do not refute previous reports identifying the capacity of these compounds to inhibit $\mathrm{A} \beta$ oligomerization, but rather discriminate those inhibitors that are more effective in preventing early stage aggregation events as opposed to those that are more effective during later stage oligomer growth and expansion. This has important implications for the design rationale of therapeutic inhibitors, as well as developing tools for dissecting the mechanism of oligomer initiation and growth. At present, knowledge of the detailed events that transition soluble monomeric A $\beta$ peptide into insoluble aggregates is incomplete. Evidence suggests that soluble $\mathrm{A} \beta$ peptide begins with an $\alpha$-helical conformation that undergoes a thermodynamically driven transition into a $\beta$-sheet conformer. This $\beta$-sheet structure positions C-terminal hydrophobic amino acids along one surface permitting the stacking of multiple $\beta$-sheet orientations driven by the exclusion of water. From the data presented here, we might expect curcumin and EGCG to interrupt these early oligomerization events by stoichiometrically binding to $\beta$-sheet conformers and preventing subsequent peptide stacking. Alternatively, these compounds may shift the equilibrium from $\beta$-sheet to $\alpha$-helical conformers and reduce the concentration of reactants in the oligomerization equation. Other demonstrated inhibitors, such as rosmarinic acid, catechin and resveratrol may associate with already formed low-molecular weight aggregates and prevent their further growth into the highermolecular weight species typically measured in dye-binding or light-scattering assays.

Identifying the precise mechanism of inhibitor action is an area of active investigation; however, regardless of subtle chemical differences between inhibitors, it is commonly held that inhibitor function requires a direct binding interaction between the compound and $A \beta$ peptide [33, 34]. This of course implies a stoichiometric relationship between inhibitor and peptide. Unfortunately, few studies address this relationship even when accurate titration data is available. In fact, using curcumin as an example, calculations made using the data from some studies [29, 70] indicate an inhibitor to peptide ratio of less than one. Assuming a direct interaction is necessary for inhibitor function, such ratios are difficult to reconcile when attempting to define mechanism of action. Perhaps the true inhibitor:peptide stoichiometries are masked in previous $A \beta$ aggregation assays because of the high starting concentrations of peptide needed for detection. If this is indeed the case, the ELISA-based assay presented here can detect oligomers with as little as $80 \mathrm{nM}$ input peptide and may provide a method to more accurately define these ratios. For example, using these lower input $A \beta$ concentrations, a stoichiometry of 10:1, curcumin:peptide can be calculated based on an $\mathrm{IC}_{50}$ value of $2 \mu \mathrm{M}$. This value is more consistent with a proposed direct binding mechanism and provides more useful information defining curcumin's effects on the early stage oligomerization reaction.

In summary, the ELISA-based $A \beta$ oligomer detection assay provides a sensitive, scalable methodology to identify and quantify small molecule inhibitors that might be present in available chemical libraries. Because of its sensitivity, less input peptide amounts are required making this assay more cost effective for expanded screening capabilities and accelerated molecular discovery. And, because this assay can discern small oligomeric structures representing the initial stages of peptide aggregation, more effective therapeutics can be identified targeting the low-molecular weight oligomers which are now regarded as the most neurotoxic species.

\section{ACKNOWLEDGMENTS}

This work was supported by the National Institutes of Health Grant AG027794 to R.A.O.

\section{REFERENCES}

[1] Findeis MA. The role of amyloid beta peptide 42 in Alzheimer's disease. Pharmacol Ther 2007; 116(2): 266-86.

[2] LeVine H. 3rd. The amyloid hypothesis and the clearance and degradation of Alzheimer's beta-peptide. J Alzheimers Dis 2004; 6(3): 303-14.

[3] Tanzi RE, Moir RD, Wagner SL. Clearance of Alzheimer's Abeta peptide: the many roads to perdition. Neuron 2004; 43(5): 605-8.

[4] Motter R, Vigo-Pelfrey C, Kholodenko D, et al. Reduction of betaamyloid peptide42 in the cerebrospinal fluid of patients with Alzheimer's disease. Ann Neurol 1995; 38(4): 643-8.

[5] Silverberg GD, Mayo M, Saul T, Rubenstein E, McGuire D. Alzheimer's disease, normal-pressure hydrocephalus, and senescent changes in CSF circulatory physiology: a hypothesis. Lancet Neurol 2003; 2(8): 506-11.

[6] Tamaoka A, Sawamura N, Fukushima T, et al. Amyloid beta protein 42(43) in cerebrospinal fluid of patients with Alzheimer's disease. J Neurol Sci 1997; 148(1): 41-5.

[7] Haass C, Selkoe DJ. Soluble protein oligomers in neurodegeneration: lessons from the Alzheimer's amyloid beta-peptide. Nat Rev Mol Cell Biol 2007; 8(2): 101-12.

[8] Kamenetz F, Tomita T, Hsieh H, et al. APP processing and synaptic function. Neuron 2003; 37(6): 925-37.

[9] Walsh DM, Klyubin I, Fadeeva JV, et al. Naturally secreted oligomers of amyloid beta protein potently inhibit hippocampal longterm potentiation in vivo. Nature 2002; 416(6880): 535-9.

[10] Walsh DM, Selkoe DJ. Oligomers on the brain: the emerging role of soluble protein aggregates in neurodegeneration. Protein Pept Lett 2004; 11(3): 213-28.

[11] Tomita T. Secretase inhibitors and modulators for Alzheimer's disease treatment. Expert Rev Neurother 2009; 9(5): 661-79.

[12] Silverberg GD, Levinthal E, Sullivan EV, et al. Assessment of lowflow CSF drainage as a treatment for AD: results of a randomized pilot study. Neurology 2002; 59(8): 1139-45. 
[13] Hammon WM. Evaluation and use of the ventriculoperitoneal shunt in hydrocephalus. J Neurosurg 1971; 34(6): 792-5.

[14] Silverberg GD, Mayo M, Saul T, Fellmann J, Carvalho J, McGuire D. Continuous CSF drainage in AD: results of a double-blind, randomized, placebo-controlled study. Neurology 2008; 71(3): 202-9.

[15] Estrada LD, Soto C. Disrupting beta-amyloid aggregation for Alzheimer disease treatment. Curr Top Med Chem 2007; 7(1): 115-26.

[16] Riviere C, Richard T, Quentin L, Krisa S, Merillon JM, Monti JP. Inhibitory activity of stilbenes on Alzheimer's beta-amyloid fibrils in vitro. Bioorg Med Chem 2007; 15(2): 1160-7.

[17] Soto C. Plaque busters: strategies to inhibit amyloid formation in Alzheimer's disease. Mol Med Today 1999; 5(8): 343-50.

[18] Talaga P. Beta-amyloid aggregation inhibitors for the treatment of Alzheimer's disease: dream or reality? Mini Rev Med Chem 2001; 1(2): 175-86.

[19] Sacchettini JC, Kelly JW. Therapeutic strategies for human amyloid diseases. Nat Rev Drug Discov 2002; 1(4): 267-75.

[20] Yamin G, Ono K, Inayathullah M, Teplow DB. Amyloid betaprotein assembly as a therapeutic target of Alzheimer's disease. Curr Pharm Des 2008; 14(30): 3231-46.

[21] Findeis MA. Approaches to discovery and characterization of inhibitors of amyloid beta-peptide polymerization. Biochim Biophys Acta 2000; 1502(1): 76-84.

[22] Haass C, Schlossmacher MG, Hung AY, et al. Amyloid betapeptide is produced by cultured cells during normal metabolism. Nature 1992; 359(6393): 322-25.

[23] Seubert P, Vigo-Pelfrey C, Esch F, et al. Isolation and quantification of soluble Alzheimer's beta-peptide from biological fluids. Nature 1992; 359(6393): 325-27.

[24] Shoji M, Golde TE, Ghiso J, et al. Production of the Alzheimer amyloid beta protein by normal proteolytic processing. Science 1992; 258(5079): 126-9.

[25] Sengupta P, Garai K, Sahoo B, Shi Y, Callaway DJ, Maiti S. The amyloid beta peptide (Abeta(1-40)) is thermodynamically soluble at physiological concentrations. Biochemistry 2003; 42(35): 1050613.

[26] Howlett DR, Perry AE, Godfrey F, et al. Inhibition of fibril formation in beta-amyloid peptide by a novel series of benzofurans. Biochem J 1999; 340 ( Pt 1) 283-9.

[27] Sabate R, Estelrich J. Pinacyanol as effective probe of fibrillar beta-amyloid peptide: comparative study with Congo Red. Biopolymers 2003; 72(6): 455-63.

[28] Torok M, Abid M, Mhadgut SC, Torok B. Organofluorine inhibitors of amyloid fibrillogenesis. Biochemistry 2006; 45(16): 537783.

[29] Yang F, Lim GP, Begum AN, et al. Curcumin inhibits formation of amyloid beta oligomers and fibrils, binds plaques, and reduces amyloid in vivo. J Biol Chem 2005; 280(7): 5892-901.

[30] Lockhart A, Ye L, Judd DB, et al. Evidence for the presence of three distinct binding sites for the thioflavin T class of Alzheimer's disease PET imaging agents on beta-amyloid peptide fibrils. J Biol Chem 2005; 280(9): 7677-84.

[31] Kim YS, Randolph TW, Manning MC, Stevens FJ, Carpenter JF. Congo red populates partially unfolded states of an amyloidogenic protein to enhance aggregation and amyloid fibril formation. J Biol Chem 2003; 278(12): 10842-50.

[32] Mishra R, Bulic B, Sellin D, Jha S, Waldmann H, Winter R. Smallmolecule inhibitors of islet amyloid polypeptide fibril formation. Angew Chem Int Ed Engl 2008; 47(25): 4679-82.

[33] Ono K, Naiki H, Yamada M. The development of preventives and therapeutics for Alzheimer's disease that inhibit the formation of beta-amyloid fibrils (fAbeta), as well as destabilize preformed fAbeta. Curr Pharm Des 2006; 12(33): 4357-75.

[34] Roher AE, Baudry J, Chaney MO, Kuo YM, Stine WB, Emmerling MR. Oligomerizaiton and fibril asssembly of the amyloid-beta protein. Biochim Biophys Acta 2000; 1502(1): 31-43.

[35] LeVine H, 3rd. Alzheimer's beta-peptide oligomer formation at physiologic concentrations. Anal Biochem 2004; 335(1): 81-90.

[36] El-Agnaf OM, Mahil DS, Patel BP, Austen BM. Oligomerization and toxicity of beta-amyloid-42 implicated in Alzheimer's disease. Biochem Biophys Res Commun 2000; 273(3): 1003-7.

[37] Kirkitadze MD, Condron MM, Teplow DB. Identification and characterization of key kinetic intermediates in amyloid betaprotein fibrillogenesis. J Mol Biol 2001; 312(5): 1103-19.
[38] Morrissey JH. Silver stain for proteins in polyacrylamide gels: a modified procedure with enhanced uniform sensitivity. Anal Biochem 1981; 117(2): 307-10.

[39] Ono K, Hasegawa K, Naiki H, Yamada M. Curcumin has potent anti-amyloidogenic effects for Alzheimer's beta-amyloid fibrils in vitro. J Neurosci Res 2004; 75(6): 742-50.

[40] Anand P, Kunnumakkara AB, Newman RA, Aggarwal BB. Bioavailability of curcumin: problems and promises. Mol Pharm 2007; 4(6): 807-18.

[41] Yang CS, Sang S, Lambert JD, Lee MJ. Bioavailability issues in studying the health effects of plant polyphenolic compounds. Mol Nutr Food Res 2008; 52(Suppl 1): 139-51.

[42] Masuda T, Hidaka K, Shinohara A, Maekawa T, Takeda Y, Yamaguchi H. Chemical studies on antioxidant mechanism of curcuminoid: analysis of radical reaction products from curcumin. J Agric Food Chem 1999; 47(1): 71-7.

[43] Wang YJ, Pan MH, Cheng AL, et al. Stability of curcumin in buffer solutions and characterization of its degradation products. J Pharm Biomed Anal 1997; 15(12): 1867-76.

[44] Byeon SR, Jin YJ, Lim SJ, et al. Ferulic acid and benzothiazole dimer derivatives with high binding affinity to beta-amyloid fibrils. Bioorg Med Chem Lett 2007; 17(14): 4022-5.

[45] Ono K, Hirohata M, Yamada M. Ferulic acid destabilizes preformed beta-amyloid fibrils in vitro. Biochem Biophys Res Commun 2005; 336(2): 444-9.

[46] Necula M, Kayed R, Milton S, Glabe CG. Small molecule inhibitors of aggregation indicate that amyloid beta oligomerization and fibrillization pathways are independent and distinct. J Biol Chem 2007; 282(14): 10311-24.

[47] Begum AN, Jones MR, Lim GP, et al. Curcumin structurefunction, bioavailability, and efficacy in models of neuroinflammation and Alzheimer's disease. J Pharmacol Exp Ther 2008; 326(1): 196-208.

[48] Cole GM, Teter B, Frautschy SA. Neuroprotective effects of curcumin. Adv Exp Med Biol 2007; 595: 197-212.

[49] Porat Y, Abramowitz A, Gazit E. Inhibition of amyloid fibril formation by polyphenols: structural similarity and aromatic interactions as a common inhibition mechanism. Chem Biol Drug Des 2006; 67(1): 27-37.

[50] Ono K, Yoshiike Y, Takashima A, Hasegawa K, Naiki H, Yamada M. Potent anti-amyloidogenic and fibril-destabilizing effects of polyphenols in vitro: implications for the prevention and therapeutics of Alzheimer's disease. J Neurochem 2003; 87(1): 172-81.

[51] Nimmrich V, Ebert U. Is Alzheimer's disease a result of presynaptic failure? Synaptic dysfunctions induced by oligomeric betaamyloid. Rev Neurosci 2009; 20(1): 1-12.

[52] Venneti S, Wiley CA, Kofler J. Imaging microglial activation during neuroinflammation and Alzheimer's disease. J Neuroimmune Pharmacol 2009; 4(2): 227-243.

[53] Inouye H, Kirschner DA. Alzheimer's beta-amyloid: insights into fibril formation and structure from Congo red binding. Subcell Biochem 2005; 38: 203-24.

[54] LeVine H, 3rd. Stopped-flow kinetics reveal multiple phases of thioflavin T binding to Alzheimer beta (1-40) amyloid fibrils. Arch Biochem Biophys 1997; 342(2): 306-16.

[55] Naiki H, Nakakuki K. First-order kinetic model of Alzheimer's beta-amyloid fibril extension in vitro. Lab Invest 1996; 74(2): 37483 .

[56] Stathopulos PB, Scholz GA, Hwang YM, Rumfeldt JA, Lepock JR Meiering EM. Sonication of proteins causes formation of aggregates that resemble amyloid. Protein Sci 2004; 13(11): 3017-27.

[57] Benseny-Cases N, Cocera M, Cladera J. Conversion of non-fibrillar beta-sheet oligomers into amyloid fibrils in Alzheimer's disease amyloid peptide aggregation. Biochem Biophys Res Commun 2007; 361(4): 916-21.

[58] Bevivino AE, Loll PJ. An expanded glutamine repeat destabilizes native ataxin-3 structure and mediates formation of parallel beta fibrils. Proc Natl Acad Sci USA 2001; 98(21): 11955-60.

[59] Ferreira ST, Vieira MN, De Felice FG. Soluble protein oligomers as emerging toxins in Alzheimer's and other amyloid diseases. IUBMB Life 2007; 59(4-5): 332-45.

[60] Tonnesen HH, Karlsen J. Studies on curcumin and curcuminoids. VI. Kinetics of curcumin degradation in aqueous solution. Z Lebensm Unters Forsch 1985; 180(5): 402-4. 
[61] Yan JJ, Cho JY, Kim HS, et al. Protection against beta-amyloid peptide toxicity in vivo with long-term administration of ferulic acid. Br J Pharmacol 2001; 133(1): 89-96.

[62] Inbar P, Bautista MR, Takayama SA, Yang J. Assay to screen for molecules that associate with Alzheimer's related beta-amyloid fibrils. Anal Chem 2008; 80(9): 3502-6.

[63] Bastianetto S, Brouillette J, Quirion R. Neuroprotective effects of natural products: interaction with intracellular kinases, amyloid peptides and a possible role for transthyretin. Neurochem Res 2007; 32(10): 1720-5.

[64] Bastianetto S, Yao ZX, Papadopoulos V, Quirion R. Neuroprotective effects of green and black teas and their catechin gallate esters against beta-amyloid-induced toxicity. Eur J Neurosci 2006; 23(1): 55-64.

[65] Sun AY, Simonyi A, Sun GY. The "French Paradox" and beyond: neuroprotective effects of polyphenols. Free Radic Biol Med 2002; 32(4): $314-18$
[66] Marambaud P, Zhao H, Davies P. Resveratrol promotes clearance of Alzheimer's disease amyloid-beta peptides. J Biol Chem 2005; 280(45): 37377-82.

[67] Kim HJ, Lee KW, Lee HJ. Protective effects of piceatannol against beta-amyloid-induced neuronal cell death. Ann N Y Acad Sci 2007; 1095: 473-82.

[68] Savaskan E, Olivieri G, Meier F, Seifritz E, Wirz-Justice A, Muller-Spahn F. Red wine ingredient resveratrol protects from betaamyloid neurotoxicity. Gerontology 2003; 49(6): 380-83.

[69] Anekonda TS, Reddy PH. Neuronal protection by sirtuins in Alzheimer's disease. J Neurochem 2006; 96(2): 305-13.

[70] Hafner-Bratkovic I, Gaspersic J, Smid LM, Bresjanac M, Jerala R. Curcumin binds to the alpha-helical intermediate and to the amyloid form of prion protein - a new mechanism for the inhibition of $\operatorname{PrP}(\mathrm{Sc})$ accumulation. J Neurochem 2008; 104(6): 1553-64.

(C) Gonzales and Orlando; Licensee Bentham Open.

This is an open access article licensed under the terms of the Creative Commons Attribution Non-Commercial License (http://creativecommons.org/licenses/by-nc/3.0/) which permits unrestricted, non-commercial use, distribution and reproduction in any medium, provided the work is properly cited. 